\title{
A Money Smart Week event The partnering of students, faculty, library, and surrounding community
}

M oney Smart Week (MSW) ${ }^{1}$ is a time when public organizations join forces with financial innovators to share information on becoming economically healthy. Designed for people of all demographics and socioeconomic levels, the events are free and strictly informative. Public libraries are excellent locations to hold such events, but how does this translate into academic libraries? After all, their primary users have already signaled they are ready and willing to invest in their future. Furthermore, how can a business librarian team up with her College of Business (COB) to supplement library programing? The marriage seems so obvious, right? Serving as the liaison to the COB has provided me the opportunity to support our business-minded individuals and help them materialize visions into growth. Their progress becomes a part of both the library's and COB faculty's success stories.

\section{Six event-filled days}

MSW began as an incentive to promote personal financial literacy. In July 2001, members of the Chicago Federal Reserve met to raise local awareness of resources available. In 2002, this transformed into six event-filled days in conjunction with community groups, financial institutions, government agencies, educational organizations, and financial experts across the nation.

\section{Responding to their need to evolve}

Like other universities, the student popula- tion in the COB at Texas A\&M UniversitySan Antonio consists of small business owners as well as potential entrepreneurs. Responding to their need to evolve, we have held events during MSW since 2014.

Entrepreneurs: Networking Your Assets and Protecting Them was a MSW event that took place April 25, 2018. This new event provided an arena to bring curiosity and questions to experts in the areas of corporate banking, commercial insurance, networking, marketing, stakeholder relations (specifically targeting the Southside of San Antonio, an economically undeveloped region), and business law. An entrepreneur mentor was also available. The setting included seven round tables, one for each specialist to facilitate by speaking to the interest and answering questions from our attendees.

\section{Because I already know I need a lot of lead time}

Planning for this event began in October 2017. Although this was the second year I partnered with MSW, I needed to refresh my understanding of all guidelines and procedures as found on the official MSW partner website. Attending webinars and reviewing their website helped me prepare. The next step was deciding this year's objective. The

Marina Lee Narvaez is business librarian at Texas A\&M University-San Antonio, email: mnarvaez@tamusa.edu

C 2018 Marina Lee Narvaez 
years prior, we had a financial advisor and an entrepreneur mentor provide informative presentations on behalf of their services. This was followed by a panel discussion comprised of local entrepreneurs ready to share their experiences. Learning from last year, I found our attendees had asked very specific questions pertaining to day-to-day business functions. I believe entrepreneurs acquire this knowledge as part of their path to success.

For example, students wanted to learn more about the art of networking. Recog- myself plenty of time to book everyone, I did not have all parties confirmed until the first part of the month the event took place. Follow-up emails provided details of the event, advertising supplements, as well as location details and parking instructions.

The logistics of the event included booking the location, setting design, creating a display, and purchasing gifts for our volunteers, door prizes for our attendees, and snacks and drinks. Public Services Manager Sarah Timm was instrumental in all these activities, as well as ensuring the required MSW survey

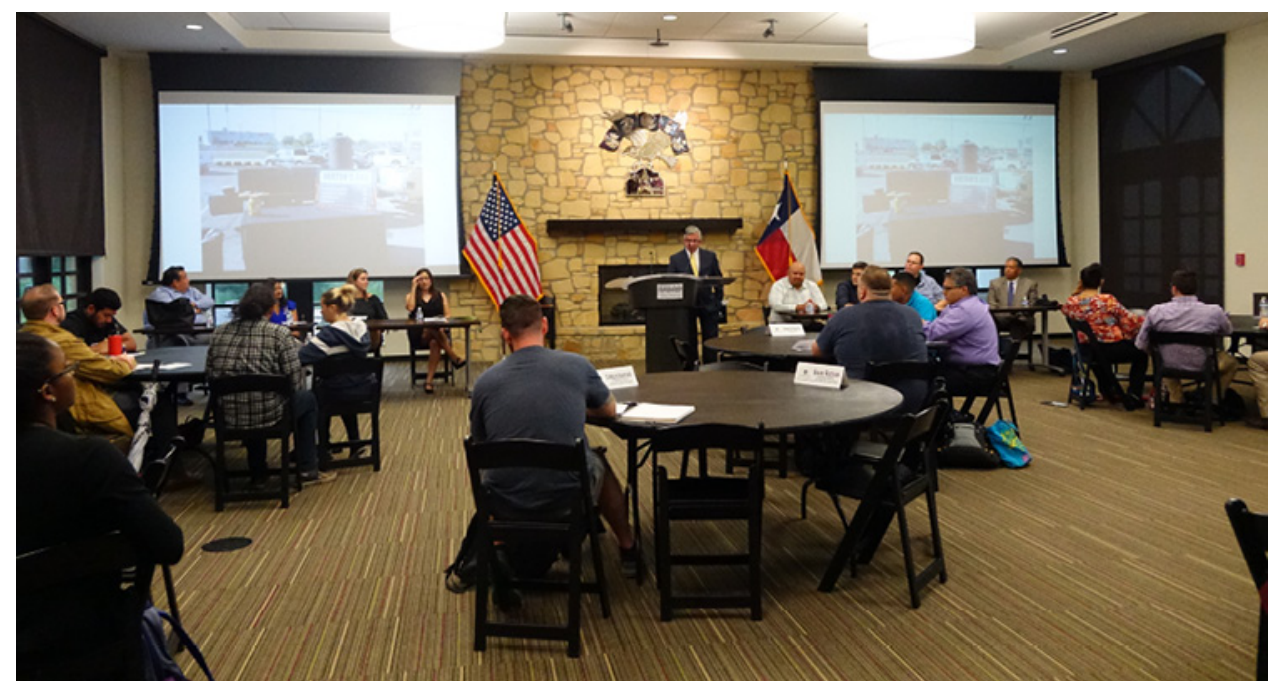

Students, faculty, library, and community partnering at the Money Smart Week event.

nizing the form of questioning, I decided that our attendees may learn more from the people entrepreneurs turn to for help. Thinking of the different facets involved when establishing a business, I compiled a list of areas to address and began reaching out to organizations for volunteer help. Along with the help of our entrepreneur instructor, Douglas Carter, we brought together our experts.

Because I already know I need a lot of lead time to secure and provide instructions for our volunteers, I began reaching out in November 2017. Some potential participants had scheduling conflicts, and identifying our keynote speaker came last. Although I gave was completed by all attendees. Attendees included 29 students and six faculty/staff. Of those, six individuals RSVP'd on the MSW official website.

Although the event appeared on the MSW official website, we still needed to do campus-generated marketing. Library Specialist Jessica Burnette assisted by creating an image for email distribution and a flyer. Using the items created by Burnette, I sent out a mass email with the flyer attached to all COB faculty. Carter followed through with a second email containing the flyer and a personalized message encouraging his colleagues to share the opportunity with their students. Television screens across campus 
advertised the event, and flyers were hung. All participants were emailed the flyer and encouraged to share details with their clients.

\section{The need for expert's advice to make progress in a small business}

I opened the festivities with a short speech offering a brief history of MSW, a review of the Money Smart Week library research guide, ${ }^{2}$ and an introduction of the participants. I designed the research guide to provide resources for personal and entrepreneurial incentives. The resources cover areas of business plans and proposals, while capturing the essence of the event by connecting the need for an expert's advice to make progress in a small business.

The opening to the event took approximately 45 minutes. The remaining $30 \mathrm{~min}$ utes of the event enabled our attendees to meet and discuss ideas and concerns with the round table facilitators. As I surveyed interactions, I noticed our attendees becoming complacent, so I asked Carter to announce the importance of moving between tables. He repeated this announcement every ten minutes or so. Our attendees and volunteers stayed late to finish up conversations. Sarah

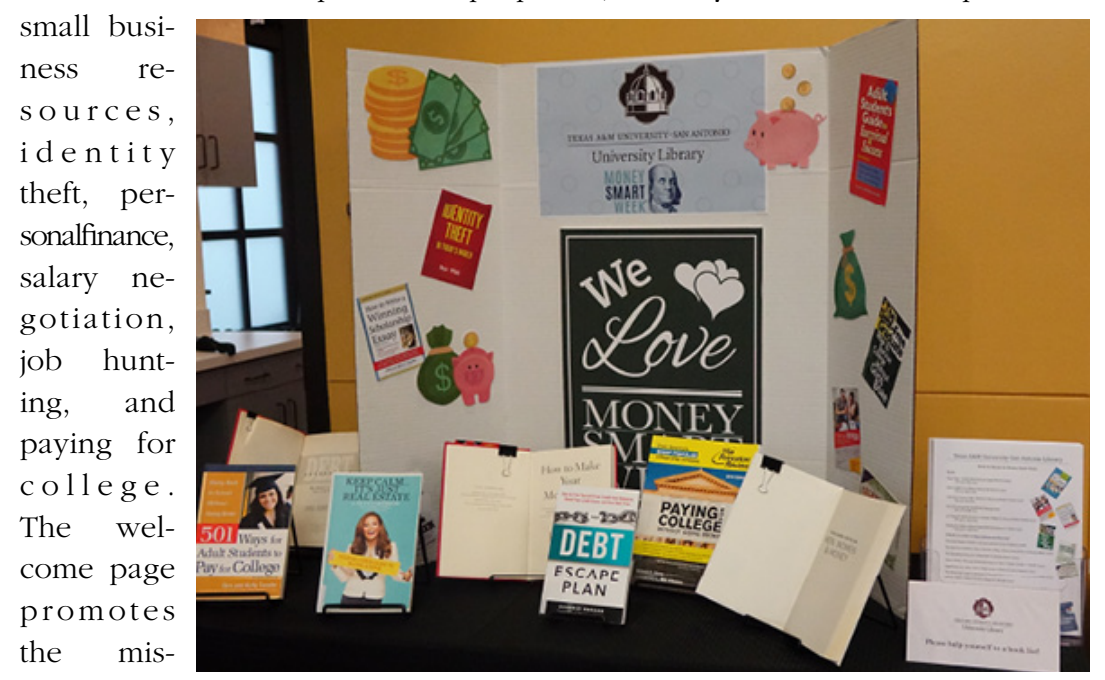

sion of the No event is complete without a display.
Timm and I completed our duties to close the event 15 minutes after the scheduled finish time.

\section{An action} plan for next year

I am very p l e a s e d with how this event turned out

Although is a way

for attendees to refer to data concerning our experts. On the welcome page, the experts and keynote speaker names are hyperlinked to websites associated with them. There were a total of 198 views of this website before the event and another 28 immediately after the event and counting.

Following my introduction, Carter presented us with a biography written by the wife of our keynote speaker Richard Barton, who then shared his experience and advice. His words of wisdom both inspired attendees to hunt goals and diluted their inflated dreams. Barton detailed humbling circumstances found on the road to success we were competing with a major storm blowing through, we had more attendees than prior years. I take with me an action plan for next year concerning terminology used in our advertisements. I say this because a participant was unclear of how to respond to the survey question regarding the type of event. In the future, I will thoroughly review the survey and apply similar verbiage on advertisements to help direct our attendees. I believe this will better capture the tone MSW puts forth, as well.

From the perspective of the students, I understand that identifying and anticipating all that is involved in establishing and maintaining a business can be very complicated. 
Exposing them to these areas might have helped them wrap their minds around the concepts involved. I hope they are able to explore and define interpretations into lessons that can suit their needs.

\section{I may add a second gathering}

Moving forward on next year's celebration, I may add a second gathering that focuses on banking specifics during the approval process for commercial loans. I thought of this idea after reading the article "The five C's of credit: The five C's of banking." 3 This article addresses the areas bankers valuate when making the decision of supplying a loan for a company's venture. The areas include cash flow, collateral, capital, character, and conditions. Similar to the event Entrepreneurs: Networking Your Assets and Protecting Them, this second event will include five round tables where bankers can facilitate discussions concerning each of the five C's. I believe this is an excellent set-up to initiate personable interactions. To prevent attendees from idling politely, I will include in my opening that this should be treated as a speed dating scenario where meeting with as many facilitators as possible will improve the chances of committing to a long-term relationship with their enterprises.

This second event also stems from a recent incentive concerning our university strategic goals of stimulating growth and development on the south side of San Antonio. The location of the university places us in a position to reach out to local businesses and add value to our neighboring stakeholders. I believe helping them to better network and protect their assets is best followed with pointers on how to implement expansion. Inviting our neighbors to attend both events responds to our strategic goals and integrates our students, faculty, and library into the surrounding community.

\section{Concluding thoughts}

Aligning library, campus, and surrounding stakeholders' goals is very important to building a strong community. Holding events helps us engage and establish relations, but as you may understand, it is not an easy task. Exploring ideas, gathering resources and support, delegating responsibilities, planning sequence of events, and so on, can test an individual's creativity and perseverance. We do this to reinforce the notion that the library is the heart of the university, and the campus as an instrumental member of the community.

\section{Notes}

1. Money Smart Week, https://www. moneysmartweek.org/about, accessed October 20, 2017.

2. Marina Narvaez, Money Smart Week, https://libguides.tamusa.edu /moneysmartweek.

3. J. Wilkinson, "5 C's of credit: 5 C's of banking," July 22, 2013, https://strategiccfo. com/5-cs-of-credit-5-cs-of-banking/, accessed April 15, 2018.

("Catalyzing organizational change," continues from page 489)

5. Peter M. Senge, The Fifth Discipline: The Art and Practice of the Learning Organization (New York: Doubleday, 2006).

6. Peter Senge, "Navigating Webs of Interdependence," YouTube video, 5:16, posted by "Social Media," September 13, 2011, https:// youtu.be/HOPfVVMCwYg.
7. "SPARC/ACRL Forum," SPARC, www. sparc.arl.org/event/sparc-acrl-forum-emerging -issues-scholarly-communication, accessed August 18, 2018, .

8. "Search Results for research agenda," ACRL Insider, https://www.acrlala.org/acrlinsider /?s=research+agenda, accessed August 18, 2018. z 